Association for Information Systems AIS Electronic Library (AISeL)

PACIS 2000 Proceedings

Pacific Asia Conference on Information Systems

(PACIS)

December 2000

\title{
Internet Diffusion in Creative Micro-Businesses- Identifying Change Agent Characteristics as Critical Success Factors
}

\author{
Pascal de Berranger \\ Manchester Metropolitan University \\ David Tucker \\ Manchester Metropolitan University
}

Follow this and additional works at: http://aisel.aisnet.org/pacis2000

\section{Recommended Citation}

de Berranger, Pascal and Tucker, David, "Internet Diffusion in Creative Micro-Businesses-Identifying Change Agent Characteristics as Critical Success Factors" (2000). PACIS 2000 Proceedings. 57.

http://aisel.aisnet.org/pacis2000/57

This material is brought to you by the Pacific Asia Conference on Information Systems (PACIS) at AIS Electronic Library (AISeL). It has been accepted for inclusion in PACIS 2000 Proceedings by an authorized administrator of AIS Electronic Library (AISeL). For more information, please contact elibrary@aisnet.org. 


\title{
Internet Diffusion in Creative Micro-Businesses Identifying Change Agent characteristics as Critical Success Factors
}

\author{
Pascale de Berranger, David E. Tucker \\ Department of Business Information Technology \\ Manchester Metropolitan University \\ Aytoun Campus, Manchester, United Kingdom, \\ M1 3GH \\ Laurie Jones
}

\begin{abstract}
Micro-businesses make a substantial contribution to the economic and social wellbeing of both Europe and the United States. In Europe for example, 30\% of firms with less than 10 employees generate $70 \%$ of turnover. This remarkable statistic has prompted the European Union to fund novel research projects aimed at stimulating growth within the very small businesses sector. In particular, projects aimed at improving the adoption rate of information and communication technology (ICT) are seen as vital. The Internet is a unique and powerful form of ICT, which has made e-commerce a reality, and micro-businesses can gain tremendous business advantages from implementing Internet technology. For this reason, this article focuses specifically on Internet diffusion processes in micro-businesses. Through a field study within a geographic cluster of creative micro-businesses, it identifies the vital role played by the change agents. It reveals that the unique way in which the change agents became infused into the local community had a significant impact on fostering mutual trust, which led to successful Internet adoption. Furthermore, this article demonstrates that the provision of customised training programs by the change agents was a critical success factor. Finally, the paper reflects upon the successful diffusion projects and identifies the characteristics of the change agents which were instrumental in ensuring Internet adoption.
\end{abstract}

Keywords: micro-business, information technology, Internet adoption and diffusion, change agents.

\section{Introduction}

Nooteboom (1988) alerted us to the fact that small businesses play as critical a role as large businesses in the world economies. Recent statistics from the Department of Trade and Industry in the United Kingdom (UK) confirm the importance of small and medium-sized enterprises (SMEs) to the British economy. Collectively they are responsible for $65 \%$ of employment and $57 \%$ of Gross Domestic Product (Madsing, 1997). SMEs are often able to gain an advantage over their larger competitors through their ability to be more responsive to new market opportunities. This is especially true in creative industries, such as music and art, where continuous innovation is important. Many SMEs however, do not possess the full range of physical or intellectual resources with which to implement and utilise Information and Communication Technologies (ICTs) to its full potential. This is a major inhibitor of Internet adoption and diffusion within SMEs.

There is a growing recognition by policy makers at European and national level that the creative sector is expanding (O'Brien and Feist, 1991; Wulf-Mathies, 1996; EU, 1998). Although there is also awareness that dynamic creative micro-businesses are vital to European global competitiveness, academic research into ICT diffusion in the creative sector is scarce with few 
published studies to date (O'Connor and Ebrey, 1996). This situation prompted the European Union to finance the Northern Quarter Network project through its Adapt and European Social funds. Additional support was provided by the UK government through its Single Regeneration Budget. The Northern Quarter is a commercial region of Manchester - the third largest city in England. Historically, the area was a manufacturing centre but is currently being regenerated and is home to numerous small creative businesses (Hill, 1995). The Northern Quarter Network Project was led by the Manchester Institute of Popular Culture, which is part of the Manchester Metropolitan University. The project lasted for two years and ended in January 1998. It was intended to provide support and development opportunities for small and micro-businesses in the creative industries sector. The rationale for this project was based on previous research which identified problems with the then current small business support structure. There was a strong training element to the project, involving practices based on a reactive as opposed to prescribed training courses (O'Connor, 1996). The focus of this article is on creative micro-businesses (i.e. those having fewer than 10 employees) which have a strong presence in the Northern Quarter and through interviews with key stakeholders, this article identifies change agent characteristics as a critical success factor in the diffusion process.

The interface between diffusion projects and potential ICTs adopters is depicted in Figure 1. It is at this interface where the encounter between change agents and first-line adopters occurs. Change agents are defined as "individuals who influence clients' innovation decisions in a direction deemed desirable by a change agency" (Rogers, 1983). A change agency is the body responsible for diffusion projects (the Manchester Institute of Popular Culture in this case). First line adopters are those organisations which initially adopt an innovation within a given group or cluster of individuals/companies.

This article examines the Northern Quarter Network project using part of Rogers' Innovation Diffusion Process model as an analytical framework. It shows how the change agents effectively utilised existing informal communication channels to provide context specific information, thereby dissipating the atmosphere of mistrust. Context specific information refers to information that has direct significance to its intended audience. Furthermore, it identifies that the provision of customised training programs, delivered only as required to individual businesses, was a reenforcing factor. The article concludes by offering fruitful areas of future research.

\section{Literature Review}

Most models and methodologies related to ICT diffusion and adoption are based on data collected in large organisations which may be inappropriate for micro-businesses (Doukidis et al., 1996). Research into large organisations tends to focus on formally documented processes. Microbusinesses, however, tend to lack such evidence due to the informality inherent in their size. This creates a need for distinct modes of inquiry which focus on informal processes. Despite the substantial amount of literature published on SMEs (e.g. Irish Management Institute, 1992; Marshall et al., 1993; Blili and Raymond, 1993; Yap and Thong, 1997), there is a scarcity of literature specifically related to micro-businesses and creative industries are particularly neglected. Similarly, although there are many papers published on technology diffusion, none was found to relate specifically to creative micro-businesses.

SMEs are often considered flexible enterprises (Levy and Powell, 1998). Some research suggests that such flexibility will make ICT adoption relatively simple to achieve (Malone, 1985; Montazemi, 1988) and that a greater speed of adoption than larger organisations might be expected 
(Storey and Cressy, 1995). These assertions appear to ignore the difficulties brought about by lack of time, cash flow issues, lack of expertise and limited knowledge of the technology, all of which typify micro-businesses (Thong and Yap, 1997). Communication issues between technology diffusers and first line adopters are similarly neglected. From the technology supply side, there is a bewildering variety of information sources. Furthermore, the use of technical jargon and the rapid pace of technological advancement serve to increase the level of complexity and uncertainty faced by micro-businesses (Geisler, 1992; Fuller, 1993; Tucker and Berranger, 2000). The literature clearly indicates that SMEs ICTs primarily for routine, administrative and operational purposes (Malone, 1985; IMI 1992; Manchester Technology Management Centre, 1997). It is not generally perceived as a strategic resource (Manchester Technology Management Centre, 1997).

Rogers (1983) model deconstructs the diffusion and adoption process into components allowing for a deeper scrutiny of each constituent. Furthermore, Rogers' framework is extremely comprehensive, having been refined and extended over a number of years (e.g. Kwon and Zmud, 1987) and provides a useful basis for examination. Rogers' model itself was not developed specifically for use within micro businesses. Consequently, this research provides a tentative application within the Northern Quarter. It aims to show that the change agents were able to use the existing informal communication channels to positively influence merging perceptions of the Internet, thereby leading to successful adoption. More recent research focussing on ICT suggests that the traditional Innovation Diffusion Process model may be insufficient to explain the diffusion process for technologies which have an inter-organisational focus, i.e. where the main impact of the technology is in multiple companies (Prescott and Conger, 1995). It is suggested that economic and critical mass theories contribute to an understanding of diffusion in this context (Prescott and Conger, 1995). Clearly the Internet falls into the category of an inter-organisational technology, hence this research has been undertaken with an appreciation that at this time, business use of the Internet has reached critical mass and that e-commerce is viable for micro-businesses. One of the many examples confirming this is of a small UK telecommunications company which is using the Internet to compete successfully with larger rivals (Oliver, 1999). This research is set in context in Figure 2.

Diffusion is seen by Rogers as a "special type of communication" (Rogers, 1983:6). Since what is being diffused is new to potential adopters, this newness (of the ideas, processes or objects) means that there is a high level of uncertainty involved. One important theme supported by both Attewell (1992) and Rogers (1983) is that information is one of the main means of reducing uncertainty. Agarwal and Prasad (1998) found that communication channels are critical to facilitating innovation adoption. Their study looks at the effects of two communication channels interpersonal and mass media - for the development of perceptions and found that, "although the importance of interpersonal channels has been widely acknowledged in the literature, mass media channels also have a key role to play". The Internet has been widely publicised in the mass media but it is questionable whether this is enough for uncertainty to diminish sufficiently to lead to adoption without interpersonal communication. This aspect will be investigated in this paper.

The role of change agents in reducing uncertainty by increasing knowledge should not be underestimated. Attewell (1992), in his theory of technology diffusion, emphasises the role of 'knowledge providers' whose responsibility it is to lower the knowledge deficiencies of potential IT adopters.

Rogers (1983:316) identified a number of factors in change agents' success, which are applied to the Northern Quarter project as follows: 
$>$ Effort in contacting clients. Effort in the context of diffusion relates to the amount of interpersonal communication with clients.

$>$ Contact timing. Participants had already gained sufficient understanding of the Internet through mass media communication to generate a propensity to join the project.

$>$ Orientation. Client orientated change agents are inclined to have a close relationship and serious credibility in the eyes of their clients, and to base their diffusion efforts on clients' needs.

$>$ Compatibility with clients' needs, knowledge of clients' attitudes, beliefs, social norms, and leadership structure. Such knowledge is necessary if the change processes are to be adapted to clients' needs.

$>$ Level of empathy with clients. Rogers hypothesised that although there is very little empirical support for this expectation, change agent success is positively related to empathy with clients.

Rogers (1983) introduces the notion of information overload in relation to the large volume of information flow in the diffusion exercise. He believes that information overload would result in breakdown and proposes that, "... by understanding the needs and problems of his or her clients, a change agent can selectively transmit to them only information that is relevant ".

The importance of interpersonal networks in the adoption or rejection of an innovation has been highlighted together with the fact that the diffusion of innovation is frequently a social as well as a technical process (Rogers, 1983:4). Lee (1994) proposes that, "beyond the issue of competition, firms and organisations also have their own sense of the world around them, or culture, which inhibits (or promotes) the sharing of new knowledge and information". The cultural compatibility of the change agents and the first line adopters is therefore important.

\section{Methodology}

This research sought to understand how the Internet was diffused to, and adopted by, the project participants. Participants' perceptions of the change agents, the project delivery and the innovation (i.e. the Internet) were sought. In epistemological terms, the research was concerned with an understanding of people's perceptions or world view (of a diffusion programme in this case) and how this might have influenced them to adopt the Internet or not. It is concerned with revealing similarities in perceptions at different stages of the adoption/diffusion process in order to isolate critical success factors to the adoption of the Internet in micro-businesses. Analysis of people's perceptions is interpretative in essence, emphasising understanding as opposed to confirmation (Miles and Huberman, 1994). Consequently the research approach adopted was to undertake in depth, semi-structured interviews with the owner managers of the SMEs in the Northern Quarter. In addition, both change agents were interviewed together with the Director of the Manchester Institute of Popular Culture (the change agency). The sampling criteria for SMEs were as follows:

$>$ interviewee had to work for a micro-business in the creative industry,

$>$ his/her organisation had to have participated in the Northern Quarter Network project and so have a web site,

$>$ he/she had to have been instrumental in the decision to adopt or not to adopt the innovation,

$>$ the organisation had to employ more than one person (i.e. sole proprietors and individuals trading as sole employee through limited organisations were not included as they were not considered to form a "company"). 
The Northern Quarter project involved a total of 15 companies' and eight of these agreed to be interviewed. All interviews were conducted by the same researcher. They were taped and transcribed. Although interviews followed an agenda, they were left sufficiently open so that comments and answers could open up the interview itself - what Stubbs (1998) calls an 'emergent approach'.

\subsection{Data Analysis}

A grounded theory approach to data analysis was chosen loosely based on Strauss and Corbin's approach (Strauss and Corbin, 1990). Interview transcripts were read and key data extracted using Rogers' "Innovation Diffusion Process" (modified) model as an interpretative framework. Each interview resulted in a cognitive map to reveal informants' perceptions of the Internet adoption process and to highlight factors they believed were enabling and constraining that process. Cognitive maps for our purpose serve as a visio spatial representation of the structure and content of an individual's belief system (Budhwar, 1996).

The Innovation Diffusion Process model divides the adoption process into categories as follow:

$>$ 'Knowledge acquisition' which relates to participants knowledge of the innovation prior to having knowledge of the project,

$>$ 'Persuasion and decision' is associated with the adoption process, and

$>$ 'Implementation' which concentrates on post adoption and use of the innovation after the project ended.

These categories were then further organised, by grouping comments appearing to pertain to the same events in the text. Each interview resulted in one map organised according to Roger's modified framework. Those maps were in turn distilled and translated to form a 'composite' map (Figure 3). This composite map forms the basis for the discussion presented in this article.

The use of an interpretative framework for data analysis is generally associated with a phenomenological approach, a view that interpretation of meaning is subjective (Lewis, 1994). This creates a number of issues regarding the validity and translation of the data, and the transferability of the research findings. To ensure that data translation was faithful, the participants themselves were asked to validate the translation through the medium of cognitive maps.

This study concentrated on the views of those businesses that went ahead with the project. The findings therefore present the views of adopters. Views of non-adopters will need to be sought in further research to provide a more complete picture of technology adoption in small creative businesses.

\section{Findings and Discussion}

This research has identified the vital importance of change agents in influencing the diffusion process from first point of contact to actual adoption of the technology. At the start of the Northern Quarter Network project, participants already possessed a propensity to adopt the Internet, but it was the change agents who were instrumental in moving them successfully to the implementation stage. Their obvious enthusiasm for the project and their belief in the viability of the project were essential prerequisites to its success. 


\subsection{Information Provision}

The change agents provided context-specific information to each micro-business. This served two important purposes. Firstly, the participants were better able to understand how the Internet could have benefits for their specific businesses. The change agents showed participants' web site from businesses in the same industry and explained the technical aspects of the web pages without using technical jargon. They also explained how the sites were being used to generate additional business. For example one business in the music industry was introduced to a web site from a rival company. The change agent guided the owner through the site, explaining both the technical and business aspects in non-technical terms. This process was successful because of the mutual trust which had already been cultivated between the change agents and the micro-businesses. This served to increase the confidence of the participants in the Internet because they could see for themselves that the benefits were real. As one respondent stated: "Before it was just talking about it and not seeing it". The second purpose was the prevention of information overload. The participants were bombarded by so much information from the mass media that they were unable to absorb it or make rational judgements based upon it. The change agents overcame this by making context-specific information available. Furthermore, the information was released only at the time when it was needed. Thus each micro-business received a customised and flexible diffusion program relevant to their specific business circumstances.

\subsection{Strategic Benefits}

Through mass media communications, the participants were aware that strategic benefits were generally attributed to the Internet. However, a combination of the high uncertainty associated with mass media communications, a general mistrust of diffusion initiatives and a lack of organisational resources had previously inhibited the adoption process. The subtle manner in with the change agents infused themselves into the Northern Quarter played a significant part in engendering the atmosphere of mutual trust, which underpinned the project.

All interviewees showed a strong awareness of the benefits of using the Internet but they had doubts, fears or uncertainties about it. These were based on either lack of knowledge of the actual technology and its use, or on a general mistrust of the information provided via mass media. Nonetheless, they we all aware of the potential benefits of using the Internet and more particularly the usefulness of a presence on the web. These comments illustrate this point:

"A web site is a publicity platform"

$>$ "You can be here and do business with someone in LA"

$>$ "It is going to become THE media, to become life"

$>$ "You can have public relations and advertising but it is someone else's interpretation. With an Internet site it is more hands on, if you are not happy you can change it"

$>$ "We wanted to be able to e-mail information as opposed to using fax or telephone. It would save us time and money"

Some of the problems associated with Internet adoption are directly linked with the characteristics of small businesses. One company explained that the problem with the Internet adoption is "getting it all set out while working flat out at the same time". This issue was common to all interviews where respondents point to a lack of time as a problem. Some interviewees linked this predicament to the needs for 'diffusers' (i.e. change agents) to take account of it in training/support programs. 


\subsection{Change Agents Characteristics}

The research showed that mass media knowledge of the benefits of Internet adoption was not in itself sufficient to lead to adoption. Those interviewed felt the need for more experientially based knowledge before they could adopt Internet technology. The 'hands on' approach used by the change agents was a critical success factor in achieving this.

The literature reviewed showed that technical knowledge transfer is better suited to interpersonal communication channels (Rogers, 1983; Attewell, 1992). Attewell added that it is the role of change agents to lower knowledge deficiencies of potential adopters. Both these assertions were verified by informants' comments. They were aware of Internet technologies through mass media communication but needed technical knowledge to reduce the uncertainty they felt towards it. Respondents relied on the change agents to fill the technical knowledge gaps. Rogers and Attewell both stressed the importance of technical knowledge at the adoption stage of diffusion. The findings suggest that technical knowledge was required earlier, at the decision stage of the adoption process.

The interviewees were asked to describe the specific characteristics of the change agents which were instrumental in their decision to adopt Internet technology. The agents were physically located in the Northern Quarter which enabled considerable face-to-face contact. This 'personal touch' was critical in building up the necessary trust between the change agents and the microbusinesses. Great importance was attached to the change agents' willingness to become involved within the Northern Quarter area. Similarly the agent's obvious understanding of creative business in general, and of the participating companies in particular, was a critical factor. The informal yet professional attitude of the agents was important as this was seen to be in alignment with the internal culture of the businesses themselves. Because of this, a mutual empathy emerged between the change agents and the businesses. Respondents rated care towards and understanding of their business, care and enthusiasm about the project itself, and general attitude, as highly important.

Another respondent explained that the problems associated with Internet adoption stem from their lack of trust in IT professionals, "IT professional are like garages and mechanics, people are afraid of putting their car in because they don't understand". This concurs with Rogers' view that lack of knowledge and the resulting lack of trust is a major inhibitor of diffusion. All respondents stated that they would have adopted Internet technology at some point. Typical comments were "I wanted to use it as a business" and "we are a creative company, we need a web site".

\subsection{Training}

Half the respondents mentioned lack of time and money as major problems when wanting to train in one aspect or another of running a business. Most respondents mentioned the need for flexibility in the training program to fit in with small business priorities.

It is interesting to note that all those interviewed but one saw the project as a joint effort between the change agents and themselves as opposed to a service, "it all came together as a community working for the same cultural end in the same area". Participants expressed how the change agents delivered training in the following terms:

"they were able to guide us" 
$>$ "it was a real process of dialogue"

$>$ "we looked at different companies' web sites where as before it was just talking about web sites. That helped us understand the capabilities of the Internet ourselves and that obviously gave us idea on where to take our sites "

$>$ "we said what we wanted and they explained the implications of our wants"

$>$ "we'd come up with an idea and they would explain how to interpret in technical terms"

Just as critical was the agents' ability to provide information in an informal yet professional manner. The businesses themselves operated in a relaxed but efficient fashion. This is an example of the cultural compatibility which existed between the change agents and the participants. Knowledge of micro-businesses characteristics and their respective industrial sector were examples of client orientation in the context of this study and contributed to the change agents' success.

\subsection{The Dissemination Process}

Surveys in the past have shown that micro-businesses harbour distrust of government initiatives (Harrer et al, 1988; Bannock, 1992; Yap et al, 1994). Interviewees, who showed a poor opinion of government initiatives in general, confirmed this. Reasons put forward for such an attitude were as follows:

$>$ Unclear aims and objectives

$>$ Lack of support

$>$ Poor value for money/efforts

$>$ Lack of understanding of the nature of and constraints experienced by micro-businesses

To overcome this in the Northern Quarter Network project the change agents made a conscious decision to become gradually infused into the local social system. They then relied on knowledge dissemination (of the project) by word of mouth through informal communication networks and introductions by third parties. This approach had the dual advantage of saving money on advertising and, more importantly, fostering trust. The information about the project "filtered down" existing communication networks. In this way, the project appeared more plausible to the participants than if it had been advertised in the mass media. Rogers (1983) highlighted how social systems could either hinder or improve the diffusion process. This unobtrusive approach used by the change agents was fundamental in allaying suspicions. Reliance on local communication networks was only possible because the change agents had been involved in local activities and attended industry-specific events and had so been accepted into the social system. The findings thus agrees with both Hackney et al 's (1996) and Charlton et al's (1997) view that, successful infiltration of the population of interest must rely on the identification and use of existing informal communication and social networks to foster trust. The research results are also in accordance with Myers (1987) who explains that micro-businesses rely on informal communication networks as a means to increase information quality. As one respondent explained: "there was no advertising, we just heard and that helped". However, this may only be possible when the target population is clustered in geographically close proximity.

Rogers (1983) stated that change agents success was related to the amount of effort in contacting clients. Clearly this research has shown that the effort expanded by the change agents at all stages of the project was considerable and had a significant influence on its success. One interviewee explained that she needed to be sure that the change agents were committed and added that she 
would otherwise not have got involved. Participants stated that they joined because they were confident that the change agents understood what their company stood for and would be able to communicate it in the right terms. It thus appears that business image is an issue. The importance of image for micro-businesses in the creative industries is specifically related to Internet adoption. This is a reflection of the Internet's position as an outward-facing, multimedia technology thus being of considerable importance in image projection. There was no mention of this in the Internet adoption literature surveyed.

Interview data suggests that empathy relates to a strong commitment to the project, commitment to the success of each organisation's web site, being involved in companies' problems and activities, and most importantly, being based in and having an understanding of the aspirations of the businesses in the Northern Quarter. The level of commitment, local presence and local involvement of the change agents increased the level of perceived empathy of the microbusinesses. Physical presence also facilitated ease of access to the change agents. This was compatible which the provision of a customised training program as described above. This research of the persuasion and decision stage is summarised in table 1.

\section{Conclusion}

Once the participants had made the decision to adopt Internet technology they were asked what benefits they believed would accrue. These were reported as access to local and international markets, direct selling, improved company profile, the ability to train others and indirect financial benefits. These answers indicated that the respondents now generally regarded the Internet as a strategic resource. This was a major change in perception from the start of the project. Benefits were also related to a better knowledge of the technology. This is a function of the training being tailored to the needs of participants as opposed to being set as a rigid agenda. All participants expressed increased confidence with the technology.

The project has provided a means of increasing local cohesion as well as improving viability through access to international markets. The Northern Quarter Network web site has raised the profile of creative activities in Manchester while allowing organisations to trade through the Northern Quarter and thus increase their viability. A strong affiliation to the area appears to have been a pre-requisite for the above.

The Northern Quarter of Manchester has two important distinguishing features which influence the generalisation to the research results. These are cohesiveness, due in the main to the geographical co-location of the businesses and their small size and homogeneity, all the businesses were in creative industries. These distinguishing features may limit the extent to which the results of this research may be more widely applied. However there are numerous examples of other districts within the United Kingdom which possess similar distinguishing features and for which this research has direct relevance. Other countries within the European Community have similar districts, such as: Temple Bar in Dublin (Ireland), Poble Nou in Barcelona (Spain), and Veemarktkwaartier in Tillburg (Netherlands). Furthermore, many of the change agent characteristics identified here are not dependent upon the distinguishing features of the Northern Quarter and are more generally applicable to technology diffusion projects.

\section{Future Research}

Rogers' theory provides a useful framework for studying diffusion projects. Research outcomes in 
the Northern Quarter were found to agree with Rogers' theory of diffusion. Further research is necessary to ascertain whether this can be generalised to micro-businesses in other industries. The root of micro-businesses uncertainty about the Internet, in this case, appeared to be mass media communication. In the first instance, what constitutes mass media in the context of Internet awareness for micro-businesses should be identified. Research should concentrate on microbusinesses according to size and type of industries, which might highlights differences.

Both Rogers (1983) and Attewell (1992) stated that the importance of technical knowledge is relatively more important at the adoption stage of diffusion. The research findings suggest that, in the case of adoption through diffusion technical knowledge is required earlier, i.e. at the 'decision' stage. This again needs further investigation. A major area of interest following directly from this research is the views and perceptions of small businesses not wishing to join such a project and/or not wishing to adopt Internet technologies. This could highlight possible reasons for nonadoption, which is important in the context of technology diffusion.

It was also highlighted that business image and its fostering, when related to Internet adoption, was a deciding factor in joining the project. Further research in this area could investigate whether this applies to other industrial sectors. The hypothesis being that creative businesses are relatively more aware of the importance of their image and the impact that an outward facing technology such as the Internet could have on company image.

As the trend towards globalisation continues inexorably, cross-national and cross-cultural research into technology diffusion will become of prime importance. It is intended that this paper should act as a catalyst to stimulate such research in countries other than the United Kingdom and hence to provide a fertile bedrock for future international collaborative projects in this field.

\section{References}

Agarwal, R., and Prasad, J. "The Antecedents and Consequences of User Perceptions in Information Technology Adoption," Decision Support Systems (22), 1998, pp.15-29.

Attewell, P. "Technology Diffusion and Organisational Learning: the case of business computing," Organization Science (3:1), 1992, pp.1-19.

Bannock, G. "Choking the Spirit of Enterprise," International Management, March 1992, pp.3033.

Blili, S., and Raymond, L. "Information Technology: Threats and Opportunities for Small and Medium-sized Enterprises," International Journal of Information management (13), 1993, pp.439-448.

Budhwar, P. S. "Cognitive Mapping Technique to Study Managerial Cognitions: Methodology Considered,” In: Manchester Business School, Working Paper no339, March 1996.

Charlton, C., Gittings, C., Leng, P., Little, J., and Neilson, I. "Diffusion of the Internet: a Local Perspective on an International Issue," In: T. McMaster, E. Mumford, E. B. Swanson, B Warboys and D. Wastell (Eds), Facilitating Technology Transfer Through Partnership, Learning from Practice and Research, IFIP TC8 WG8.6., 1997, pp.337-354, London: Chapman and Hall. 
Doukidis, G. I., Lybereas, P., and Galliers, R. D. "Information System Planning in Small Business: A Stage of Growth Analysis," Journal of Systems Software (33), 1996, pp.189-201.

Department of Trade and Industry, "Small Firms in Britain Report," 1995, pp.11, London: HMSO.

European Union. "Culture, the Cultural Industries and Employment," Commission Staff Working Paper SEC(98)837, part 3 Conclusions, http://europa.eu.int/search97cgi// 1998

Fuller, E. "Business Development through IT Adoption - A Learning Agenda," 39th ICSB World Conference, 1993, in Obrecht, J. J., Bayad, M. (eds.), "Business and its Contribution to Regional and International Development", Robert Schuman University, Strasbourg, 1994, pp.95-104.

Geisler, E. "Information Technology Department," IEEE Transactions on Engineering Management (39:2), 1992, pp.112.

Hackney, R., Kawalek, J., and Dhillon, G. "Information Technology and Communication Management Within SMEs: Opportunities for Partnership," UKAIS Conference, Southampton University, 2-4 April 1996.

Harrer, B. J., Weijo, R. O., and Hattrup, M. P. "The Role of Change Agents in New Product Adoption," Industrial Marketing Management (USA) (17:2), 1988, pp.95-102.

Hill, D. "The northern quarter network," Institute for Popular Culture, Autumn1995, [on-line] http://es-www.mmu.ac.uk:81/cgi-bin/betsie/parser2.pl/www.mmu.ac.uk/h-ss/mipc/nqnrept1.htm, Part 1-4, 1995.

Irish Management Institute. "Microcomputers in the Administration and Management Processes in Smaller Business: The Emerging Experience in EEC Countries," Commission of the European Communities, 1992.

Julien, P. A. "New Technologies and Technological Information in Small Business," Journal Of Business Venturing (10), 1995, pp.459-475.

Kwon, T. H. and Zmud R. W. "Unifying the Fragmented Models of Information Systems Implementation," In Boland, R.J. and Hirschheim, R.A. (Eds.), Critical Issues in Information Systems Research, 1987, New York: John Wiley and Sons, pp. 227-251.

Lee, A. S. "Electronic Mail as a Medium for Rich Communication - an empirical investigation using hermeneutic interpretation," MIS Quarterly (18:2), 1994, pp.143-157.

Levy, M. and Powell, P. "SME Flexibility and the Role of Information Systems," Small Business Economics (11), 1998, pp.183-196.

Lewis, P. Information Systems Development, 1994, Pitman, pp.139.

Malone, S. C. "Computerizing Small Business Information Systems," Journal of Small Business Management, April, 1985, pp.10-16.

Manchester Technology Management Centre. "The North West Regional Business Usage of 
Information and Communications Technology Survey," MTMC Manchester, Internal Report, 1997.

Madsing, D. "NCC presentation on the Information Technology Initiative," Manchester Metropolitan University, December 1997.

Marshall, J. N. et al. "The Impact of Government-assisted Management Training and Development on Small and Medium-sized Enterprises in Britain," Environment and Planning CGovernment and Policy (11:3), 1993, pp. 331-348.

Miles, M. B., and Huberman, A. M. Qualitative Data Analysis, 2nd Edition, 1994, Sage Publications.

Montazemi, A. R. "Factors Affecting Information Satisfaction in the Small Business Environment," MIS Quarterly, June, 1988, pp. 239-256.

Myers, M. D. "Qualitative Research in Information Systems," Living Scholarship, MISQ Discovery, [on-line] http://www.auckland.ac.nz/msis/isworld/index.html, 1996, pp. 1-12.

Nooteboom, B. "The Facts about Small Business and the Real Values of its 'Life World', American Journal of Economics and Sociology (47:3), 1988, pp. 299-314.

O'Brien, J., and Feist, A. "Employment in the Arts and Cultural Industries: an Analysis of the 91 Census," Art Council of England, Research Report No. 2, 1995.

O’Connor, J. “ESF Adapt - Northern Quarter; Networking for Business Advantage,” Newsletter Number 1, Manchester Institute of Popular, Manchester Metropolitan University, Nov/Dec 1996, pp. 4.

O'Connor, J., and Ebrey, J. "Cultural Production: Action Research Project - Review of Existing Research,” Internal Report, Manchester Institute of Popular Culture, 1996, pp. 6.

Oliver, D. “Branding by Numbers,” Internet Works (18), 1999, pp. 34.

Prescott, M. B., and Conger, S. A. "Information Technology Innovations: A Classification by IT Locus of Impact and Research Approach," The DATA BASE for Advances in Information Systems (26:2) 1995, pp. 20-41.

Rogers, E. M. Diffusion of Innovation, 1983, pp.92, New York: The Free Press.

Storey, D. J., and Cressy, R. "Small Business Risk: A Firm and Bank Perspective," Warwick Business School SME Centre, Working Paper, 1995, In Levy, M. and Powell, P. "SME Flexibility and the Role of Information Systems", Small Business Economics (11), 1998, pp.183.

Stubbs, M. "Dealing with Complex Issues: Networking, Creative Dialogue and a Sense of Audience in Environmental Management," PhD. Thesis, Cranfield University, UK, 1998.

Tucker, D., and Berranger, de P. "Nurturing Trust and Reactive Training: Essential Elements in ICT Diffusion Projects,” IRMA International Conference Proceedings, Anchorage, Alaska, USA, 
May 21st - 24th, 2000 (Forthcoming).

Wulf Mathies. "Culture and Structural Policies: A Contribution to Employment," Wulf Mathies, Minister of the European Commission responsible for regional policy and cohesion, Meeting of ministers responsible for Regional Policy and special Planning, Venice, 3-4 May 1996, in O’Connor, J. "Initial Feasibility Study: Cultural Industries Support services", Manchester Institute of Popular Culture, Manchester Metropolitan University, 1997.

Yap, C. S., and Thong, J. Y. L. "Programme Evaluation of a Government Information Technology Programme for Small Businesses,” Journal of Information Technology (12), 1997, pp. 107-120.

Yap, C. S., Thong, J. Y. L., and Raman, K. S. "The Effect of Government Incentives on Computerisation in Small Business," European Journal of Information Systems (3:3), 1994, pp.191-206.

\section{FIGURES AND TABLES}

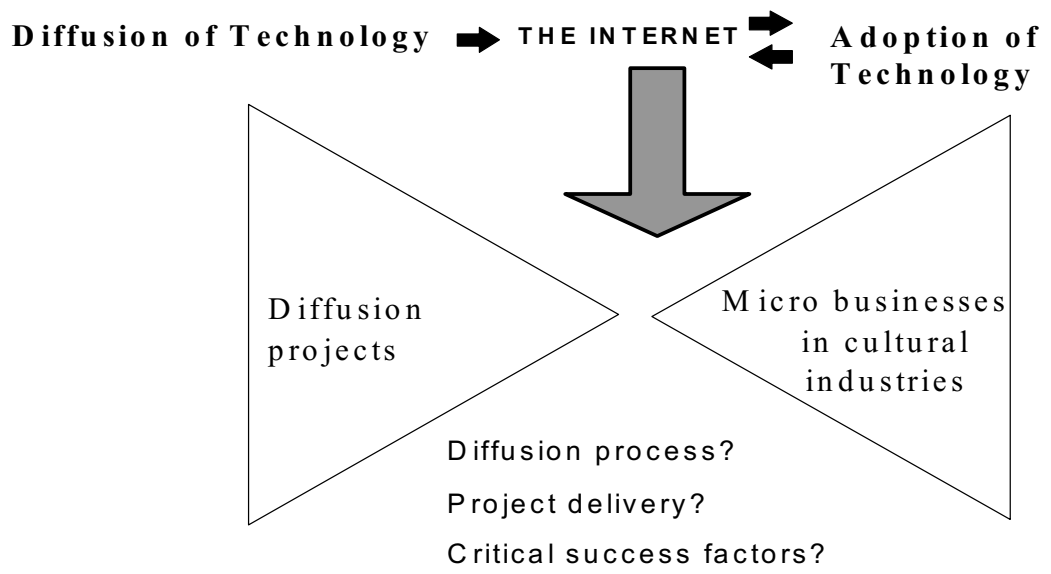

Figure 1: Northern Quarter Network project research in context 


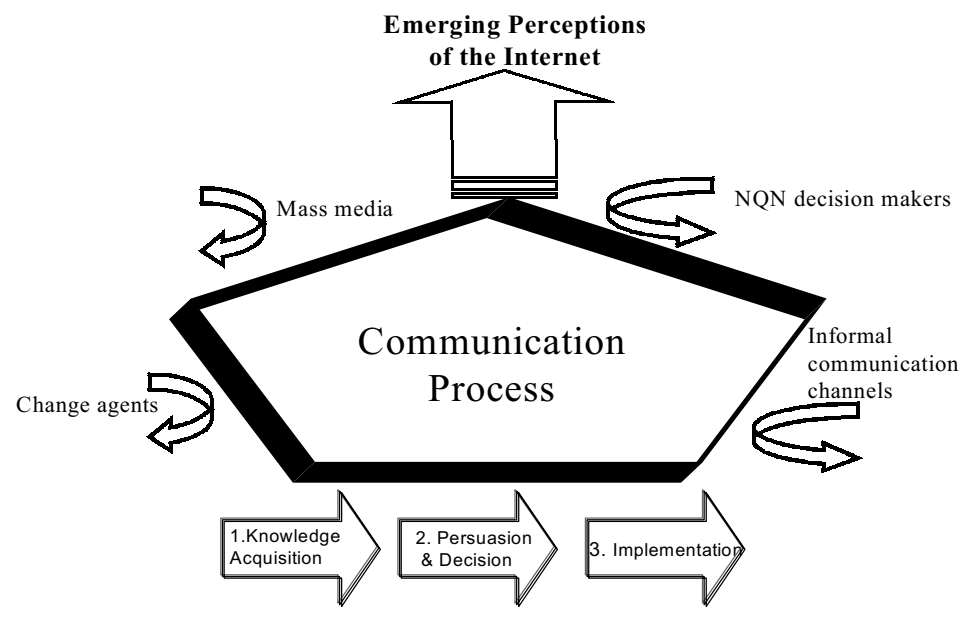

Figure 2: Stages in the innovation adoption process. Adapted from Rogers (1983:165) 


\section{TRANSLATED COMPOSITE MAP}

Knowledge Acquisition

\section{THE INTERNET}

$>$ Perceived need to be on the Internet

$>$ Clear intention to adopt

$>$ Lack of knowledge of both the technology itself and its uses for business

$>$ Certain level of uncertainty and in some cases fear

\section{OTHER INITIATIVES} GENERAL

$>$ Poor opinion in general

$>$ Unclear aims and objectives

$>$ Poor value for money/effort

$>$ Perceived lack of support

$>$ Lack of understanding of the nature of small businesses

PROJECT PROCESS

$>$ Access difficulties

$>$ Importance of location

$>$ Training content level

$>$ Selection criteria

\section{NORTHERN QUARTER}

$>$ Strong affiliation to the area

$>$ Dependence on the area for business survival and/or growth

\section{Persuasion and decision}

\section{INFUSION}

> Attendance/involvement at local events/activities

$>$ Attendance/involvement at industry specific events

$>$ Reliance of local social communication network for information dissemination

$>$ Reliance on third part introduction

\section{CHARACTERISTICS OF CHANGE}

\section{AGENTS}

$>$ Understanding of $\mathrm{SBs}$ priorities

$>$ Office in the NQ

$>$ An exchange, not a hand out

$>$ Knowledge of individual businesses

$>$ Knowledge of relevant industries r...

\section{TRAINING/SUPPORT}

$>$ Provide guidance

$>$ Flexibility, adaptability and availability

$>$ Collaboration and dialogue

$>$ Provide technical knowledge as and when required

$>$ Information provided in context

$>$ Distinct roles

$$
\text { TTn - f f n.mentum }
$$

\section{REASONS FOR JOINING THE PROJECT}

$>$ Confidence that "these people" understood company's ethos and would communicate it in the right way

$>$ Belief that project workers understood what the NQ was about

$>$ Belief that project would not damage company's image

$>$ Free training

$>$ Free web site

\section{Implementation}

\section{COMPANIES' WEBSITES}

$>$ It made us money in the sense that the word spread, people heard about us

$>$ The web makes things more equal between large and small companies

It is an advert for the gallery

$>$ It is helping the company profile wise around the world

- W/e have a mail order cection W/e

\section{BENEFITS OF THE PROJECT}

$>$ Increased local and global communication

$>$ Greater understanding of the technology thus leading to reduced level on uncertainty

$>$ Increased prestige

$>$ Increased cohesion and economic viability of the whole area

Figure 3: composite map 


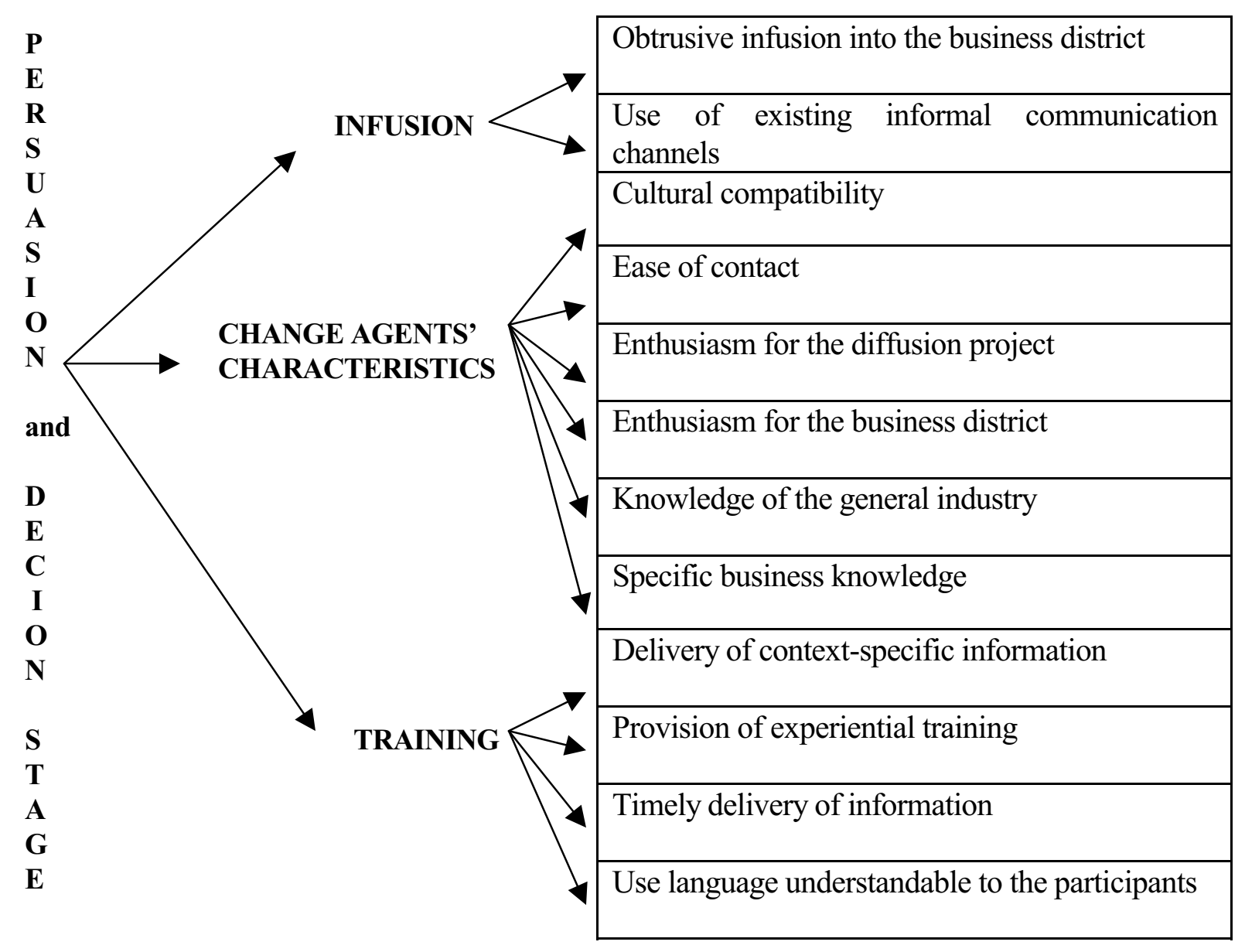

Table 1: Characteristics of Change Agents as Critical Success factors in the Innovation Diffusion Process 